\title{
Humoral Hypercalcemia of Malignancy \\ Release of a Prostaglandin-stimulating Bone-resorbing Factor In Vitro by Human Transitional-Cell Carcinoma Cells
}

\author{
F. Richard Bringhurst, Barbara E. Bierer, Francois Godeau, Nancy Neyhard, Valerie Varner, and Gino V. Segre \\ Endocrine Unit, Massachusetts General Hospital, Boston, Massachusetts 02114
}

\begin{abstract}
Secretion by tumor cells of circulating bone-resorbing factors may frequently underlie the hypercalcemia that occurs in patients with malignancy. Efforts to identify the responsible mediators have been hampered by a lack of available human tumor cell systems suitable for study of the pathogenesis of the humoral hypercalcemia syndrome. We have established a transitionalcell carcinoma (TCC) line in vitro from a patient with humoral hypercalcemia. These cells are tumorigenic and cause hypercalcemia in athymic nude mice. Culture medium conditioned by TCC cells contains potent bone-resorbing activity in vitro, the physical and biological properties of which are similar to those of bone-resorbing activity present in the original patient's urine. The bone-resorbing activity of the TCC factor is accompanied by increased prostaglandin release from bone and is blocked by indomethacin and calcitonin. The TCC-derived bone-resorbing activity coelutes with prostaglandin-stimulating activity during gel filtration with an approximate molecular weight of 15,000 . This activity is nondialyzable, stable to concentrated urea and reducing agents, and destroyed by boiling. The TCC factor does not increase cyclic AMP production in bone or kidney bioassays and does not exhibit transforming growth factor activity. We conclude that a unique macromolecular factor released by TCC cells causes bone resorption by a mechanism dependent upon stimulation of bone cell cyclooxygenase, and that this factor is the probable cause of the hypercalcemia in vivo. The TCC cell line provides a new model for study of the human humoral hypercalcemia syndrome.
\end{abstract}

\section{Introduction}

Hypercalcemia occurs frequently in advanced malignancies and often severely compromises management of the underlying neoplasm (1-3). Accelerated net bone resorption is believed to be the source of the hypercalcemia in such patients $(1,4,5)$, although understanding of the mechanisms whereby malignant cells alter the functions of normal bone cells remains incomplete. Direct osteolysis by tumor cells metastatic to bone may occur (6). Often, however, circulating tumor-derived bone-resorbing

This work was presented in part at the Sixth Annual Meeting of the American Society for Bone and Mineral Research, Hartford, CT, 2629 June 1984.

Dr. Bierer is currently with the Dana Farber Cancer Institute, Boston, MA 021 14; Dr. Godeau is with the Institut Pasteur, Paris, France. Address reprint requests to Dr. Bringhurst.

Received for publication 4 April 1985.

J. Clin. Invest.

(c) The American Society for Clinical Investigation, Inc.

0021-9738/86/02/0456/09 \$1.00

Volume 77, February 1986, 456-464 factors appear to cause osteolysis, most clearly so in those patients whose hypercalcemia occurs in the absence of skeletal metastases (7). The pathogenesis of this humoral hypercalcemia syndrome appears to be heterogeneous. Secretion by tumor cells of a variety of bone-resorbing factors has been postulated, including parathyroid hormone $(\mathrm{PTH})^{1}(8-10)$, prostaglandins $(11-13)$, osteoclast-activating factor and other leukocyte products (14-17), transforming growth factors $(1,18,19)$, and agents with PTHlike actions on bone and kidney (20-22).

Efforts to purify and characterize unknown bone-resorbing factors derived from human tumors have been impeded by the relative insensitivity of available in vitro bone resorption bioassays and, more importantly, the limited availability of human tumor tissue as a source of active factors. We have recently established a continuous tumor cell line from a patient with transitional-cell carcinoma (TCC) and humoral hypercalcemia. These tumor cells cause hypercalcemia when implanted in athymic nude mice and release a potent bone-resorbing factor in vitro that exhibits properties distinguishing it from agents previously implicated in the genesis of the humoral hypercalcemia of malignancy syndrome. The studies reported here provide the basis for a new model of human hypercalcemia of malignancy.

\section{Methods}

\section{Clinical summary}

The patient was a 54-year-old Caucasian woman who was found to be hypercalcemic $(12.6 \mathrm{mg} / 100 \mathrm{ml})$ when admitted for a hypertensive lacunar stroke in February 1983. She had a history of alcoholism and was taking hydrochlorothiazide for mild hypertension. In 1981, serum calcium and phosphorus had been noted to be 10.6 and $1.7 \mathrm{mg} / 100 \mathrm{ml}$, respectively. Evaluation of the hypercalcemia revealed an undetectable plasma amino-terminal immunoreactive PTH (iPTH) $(<8 \mathrm{pg} / \mathrm{ml})$, low serum $1,25(\mathrm{OH})_{2} \mathrm{D}(15 \mathrm{pg} / \mathrm{ml})$, elevated carcinoembryonic antigen $(45 \mathrm{ng} / \mathrm{ml})$, and urine cytology positive for TCC. $\mathrm{A}^{99 \mathrm{~m}} \mathrm{Tc}$ diphosphonate bone scan showed a generalized increase in skeletal uptake but no focal lesions. 24-h urinary calcium excretion was $160 \mathrm{mg}$. The following studies were normal: blood urea nitrogen, creatinine, alkaline phosphatase, urinary Bence-Jones protein, serum immunoelectrophoresis, chest $\mathrm{x}$-ray, and liver-spleen scan. Serum calcium and phosphorus ranged between 12.6 and $13.7 \mathrm{mg} / 100 \mathrm{ml}$ and between 3.3 and $5.7 \mathrm{mg} / 100 \mathrm{ml}$, respectively, and creatinine gradually rose to $2.5 \mathrm{mg} / 100 \mathrm{ml}$. Hypercalcemia and azotemia failed to respond to discontinuation of the diuretic, intravenous hydration, or oral orthophosphate but were successfully managed with mithramycin. Diffuse retroperitoneal node involvement was found at laparotomy, and a portion of an excised lymph node was used to establish the cell line reported here.

1. Abbreviations used in this paper: DME, Dulbecco's modified Eagle's medium; EGF, epidermal growth factor; $\mathrm{PGE}_{2}$, prostaglandin $\mathrm{E}_{2} ; \mathrm{PTH}$, parathyroid hormone; bPTH, bovine PTH; iPTH, immunoreactive PTM; ROS, rat osteosarcoma (cell); TCC, transitional-cell carcinoma; TGF, transforming growth factor. 
Tumor burden and hypercalcemia responded to repetitive courses of intravenous methotrexate, but urinary frequency ultimately prompted readmission in September 1983, when cystoscopy showed the bladder to be filled with tumor. Renal function had remained normal since her previous discharge, however, and urine cultures were negative. During this admission, serum calcium and phosphorus ranged between 9.7 and $12.4 \mathrm{mg} / 100 \mathrm{ml}$ and between 2.1 and $2.8 \mathrm{mg} / 100 \mathrm{ml}$, respectively, a third bone scan was unchanged, and a total of eight 24-h urine collections were performed for measurement of urinary cyclic AMP excretion, the mean \pm standard error of the mean of which was $4.8 \pm 0.8 \mathrm{nmol} / 100 \mathrm{ml}$ glomerular filtrate. These and others were also concentrated for study of urinary bone-resorbing activity, as described below. Over the next 3 mo, further progression of locally metastatic disease occurred despite chemotherapy, renal failure resulting from ureteral obstruction ultimately supervened, and the patient expired. Permission for an autopsy was not granted.

\section{Culture of tumor cells}

Tumor tissue obtained at surgery was minced to 1-2-mm fragments in $100-\mathrm{mm}$ plastic petri dishes containing $15 \mathrm{ml}$ of Dulbecco's modified Eagle's medium (DME) supplemented with 5\% fetal bovine serum (" $5 \%$ DME"). Explants (10-20 fragments per dish) were incubated at $37^{\circ} \mathrm{C}$ in a humidified atmosphere of $5 \% \mathrm{CO}_{2}$ in air with medium changes once or twice each week. Homogeneous populations of polygonal tumor cells grew out from these explants and were maintained in 5\% DME with serial subculturing by trypsinization at 3-4-wk intervals. $3 \mathrm{~d}$ after feeding confluent monolayers of these tumor cells in $150-\mathrm{cm}^{2}$ flasks with $5 \%$ DME, the medium was discarded and replaced with $25 \mathrm{ml}$ of DME containing $0.5 \%$ horse serum. The conditioned medium was then harvested after $2 \mathrm{~d}$ and the procedure was repeated once before returning the cells to 5\% DME. The conditioned medium was centrifuged at 2,000 $g$ for $15 \mathrm{~min}$ and stored at $-20^{\circ} \mathrm{C}$ until further processing.

\section{Tumor growth in athymic nude mice}

Freshly trypsinized tumor cells, washed once with 5\% DME, were resuspended in serum-free DME at 2-4 $\times 10^{6} \mathrm{cells} / \mathrm{ml}$ and administered subcutaneously $(0.5 \mathrm{ml}$ per animal) to athymic nude mice (nu AF, Harlan Sprague Dawley, Inc., Indianapolis, IN). Animals were maintained on standard mouse laboratory diet in germ-free cages and were observed weekly for evidence of tumor growth, which occurred in $\sim 4 \mathrm{wk}$. Thereafter, blood was obtained at 1-2 wk intervals for measurement of calcium and creatinine. At the time of sacrifice, tumor-bearing mice were carefully examined for evidence of visceral or bony metastases. In some cases, ${ }^{99 \mathrm{~m}} \mathrm{Tc}$ diphosphonate bone scans of normal and hypercalcemic tumorbearing nude mice were kindly performed by Dr. Frank Castronova (Radiation Safety Unit, Massachusetts General Hospital).

\section{Preparation of medium and urine concentrates}

Cell-conditioned medium was thawed and centrifuged at $2,000 \mathrm{~g}$ prior to concentration. Urine samples were filtered serially through glass depth prefilters and 1.2- and 0.45- $\mu \mathrm{m}$ membrane filters (Gelman Sciences, Inc., Ann Arbor, MI) upon arrival in the laboratory and immediately concentrated at $4^{\circ} \mathrm{C}$. All samples were concentrated 100 -fold by ultrafiltration under nitrogen using thin-channel and stirred-cell devices fitted with YM5 membranes (nominal mol wt cutoff, 5,000) (Amicon Corp., Danvers, MA). Preliminary studies showed no increase in recovery of boneresorbing activity when UM2 membranes $(1,000 \mathrm{~mol} \mathrm{wt})$ were used. Supernatants obtained after centrifugation of the concentrates at 50,000 $g$ for $2 \mathrm{~h}$ and stored at $-20^{\circ} \mathrm{C}$ exhibit no loss of bone-resorbing activity over periods of several months.

\section{Bone resorption bioassay}

Bone resorption was quantitated by the release of previously incorporated ${ }^{45} \mathrm{Ca}$ from newborn mouse calvarial bones in vitro. Half-calvaria from 5-d-old mice (CD-1 strain, Charles River Breeding Laboratories, Inc., Wilmington, MA) were obtained as previously described (23) after maternal administration of $50 \mu \mathrm{Ci}$ of ${ }^{45} \mathrm{CaCl}_{2}$ (New England Nuclear, Boston, MA) subcutaneously on the 19 th day of gestation. The bones were pre- cultured in $2 \mathrm{ml}$ of DME containing $1 \mathrm{mM}$ calcium, $2 \mathrm{mM}$ phosphate, $5 \%$ heat-inactivated horse serum, and $1 \%$ antibiotic/antimycotic solution (Gibco, Grand Island, NY) on a rocking platform at 50 oscillations/min in a $37^{\circ} \mathrm{C}$ incubator under $5 \% \mathrm{CO}_{2}$ in air. After $24 \mathrm{~h}$, the medium was replaced with $3 \mathrm{ml}$ of medium that contained test substances (or vehicle alone) sterilized by membrane filtration $(0.45 \mu \mathrm{m}$, Gelman Sciences, Inc.). Synthetic bovine PTH(1-34) (bPTH) $(6,000 \mathrm{U} / \mathrm{mg})$ was dissolved in $0.005 \mathrm{M}$ acetic acid, and cortisol (Steraloids Co., Wilton, NH) and indomethacin (Sigma Chemical Co., St. Louis, MO) were stored as concentrated stocks in methanol at $-20^{\circ} \mathrm{C}$. The acetic acid and methanol vehicles, at concentrations of $0.5 \%$ and $0.1 \%$, respectively, had been found not to affect the release of ${ }^{45} \mathrm{Ca}$ from control bones. After an additional $72 \mathrm{~h}$, the bones were removed, rinsed in saline, and placed in plastic scintillation vials containing $0.4 \mathrm{ml}$ of $2 \mathrm{~N} \mathrm{HCl}$. Aliquots of culture medium $(1 \mathrm{ml})$ were transferred to separate vials containing $4 \mathrm{ml}$ of scintillation fluid (Scint-A, Packard Instrument Co., Inc., Downers Grove, IL) for determination of released radioactivity. Bone extracts were counted similarly, and the percentage of total bone ${ }^{45} \mathrm{Ca}$ released into the medium during the 72-h treatment period was calculated. Results were expressed as the mean \pm standard error of the mean of the percentage of ${ }^{45} \mathrm{Ca}$ released for groups of five or six bones, and the statistical significance of differences between groups was evaluated by Student's $t$ test. Epidermal growth factor (EGF), at doses between 0.1 and $100 \mathrm{ng} / \mathrm{ml}$, did not significantly increase resorption in this system after $72 \mathrm{~h}$ in the absence of added calf serum.

\section{Adenylate cyclase activity}

Adenylate cyclase activity in isolated canine renal membranes was measured as the rate of conversion of $\left[{ }^{32} \mathrm{P}\right] \mathrm{ATP}$ to $\left[{ }^{32} \mathrm{P}\right]$ cyclic AMP in the presence of guanyl nucleotides, as described by Nissenson et al. (24) with minor modifications. The final concentrations of ATP and guanylimidodiphosphate in the assay were $0.52 \mathrm{mM}$ and $70 \mu \mathrm{M}$, respectively. Test samples of PTH standard were added in a volume of $0.01 \mathrm{ml}$ to provide a final incubation volume of $0.1 \mathrm{ml}$. Recovery of $\left[{ }^{3} \mathrm{H}\right]$ cyclic AMP after Dowex and alumina chromatography was typically $75-85 \%$. Results were expressed as picomoles per milligram of membrane protein $/ 30 \mathrm{~min}$ for triplicate determinations.

\section{Cyclic AMP production}

Rat osteosarcoma (ROS) cells. Monolayers of ROS 17/2.8 clonal ROS cells, kindly provided by Dr. Gideon Rodan (Department of Oral Biology, University of Connecticut, Farmington) were grown to confluence in Ham's F-12 medium with 5\% fetal bovine serum and $1 \%$ kanamycin (Gibco) in 16-mm wells. Cells were incubated first at $37^{\circ} \mathrm{C}$ in air for 30 min in $0.5 \mathrm{ml}$ of PAG buffer (phosphate-buffered saline with $2 \mathrm{mg} / \mathrm{ml}$ of glucose and $4 \mathrm{mg} / \mathrm{ml}$ of heat-inactivated bovine albumin), this buffer was discarded, and test agents were then added in $0.2 \mathrm{ml}$ of PAGI buffer (PAG with $1 \mathrm{mM}$ isobutylmethylxanthine). Incubations were terminated after $10 \mathrm{~min}$ by addition of cold methanol $(1 \mathrm{ml} /$ well $)$, the cell layers were extracted twice more with methanol, the combined extracts were evaporated by vacuum centrifugation, and the dried extracts were redissolved in acetate buffer for measurement of cyclic AMP by a specific radioimmunoassay (New England Nuclear). Significant stimulation of cyclic AMP in this bioassay was routinely observed at concentrations of bPTH $(1-34)>0.5 \times 10^{-9} \mathrm{M}$. Concentrates were also tested for stimulation of conversion of $\left[{ }^{3} \mathrm{H}\right]$ adenine to $\left[{ }^{3} \mathrm{H}\right]$ cyclic AMP in intact ROS cells (after $7 \mathrm{~d}$ of pretreatment with dexamethasone), as kindly performed by Dr. Gideon Rodan. The sensitivity of this bioassay for bPTH is $\sim 0.01-$ $0.03 \times 10^{-9} \mathrm{M}(25)$.

Calvarial bones. Neonatal mouse calvaria were obtained as above and incubated at $37^{\circ} \mathrm{C}$ in PAG buffer for up to $1 \mathrm{~h}$ before transfer of individual bones to siliconized (Sigmacote, Sigma Chemical Co.) glass tubes containing test agents in $0.25 \mathrm{ml}$ of PAGI buffer. Reactions were conducted for $10 \mathrm{~min}$ at $37^{\circ} \mathrm{C}$ and terminated by addition of $1 \mathrm{ml}$ of cold methanol. Bones were sonicated for $30 \mathrm{~min}$ at room temperature, the methanol extraction was repeated twice, and the combined extracts were then evaporated and processed for cyclic AMP radioimmunoassay as described above. Significant stimulation of calvarial cyclic AMP was 
usually evident at concentrations of bPTH(1-34) between 0.5 and 1.0 $\times 10^{-9} \mathrm{M}$. In some experiments, cyclic AMP was measured directly in aliquots of medium obtained at $72 \mathrm{~h}$ from the bone resorption bioassay.

\section{Prostaglandin synthesis}

Prostaglandin $\mathrm{E}_{2}\left(\mathrm{PGE}_{2}\right)$ in medium from cultures of mouse calvaria was determined by specific radioimmunoassay (New England Nuclear) after appropriate dilution of the media in assay buffer. Control culture media at these dilutions were found not to interfere with measurement of added standard $\mathrm{PGE}_{2}$ in this assay.

\section{Epidermal (EGF) and transforming (TGF) growth factor activities}

Binding of ${ }^{125}$ I-labeled murine EGF to human A431 cells was studied as described by DeLarco et al. (26) except that cells, grown in 5\% DME, were plated at $1.25 \times 10^{4}$ cells $/ \mathrm{cm}^{2}$ in $16-\mathrm{mm}$ plastic wells $24 \mathrm{~h}$ before study. Radioiodinated murine EGF $(170 \mu \mathrm{Ci} / \mu \mathrm{g}$, Collaborative Research Co.) was added $(30,000 \mathrm{dpm} / 0.35 \mathrm{ml})$ to wells containing $0.5 \mathrm{ml}$ of test samples or standard EGF (Biomedical Technologies Inc., Cambridge, $\mathrm{MA})$, and specific binding was determined after $60 \mathrm{~min}$ at $20^{\circ} \mathrm{C}$.

Induction of anchorage-independent growth of non-neoplastic rat cells was assessed essentially as described by Roberts et al. (27). Briefly, normal rat kidney cells (clone 49F) were plated at a density of 500 cells per microtiter well in $0.2 \mathrm{ml}$ of DME containing $0.3 \%$ agarose and $10 \%$ calf serum (Flow Laboratories, Inc., McLean, VA) with or without EGF $(5 \mathrm{ng} / \mathrm{ml}$, Collaborative Research Co., Lexington, MA). Cells were incubated for $7 \mathrm{~d}$ in a humidified atmosphere of $10 \% \mathrm{CO}_{2}$ in air and then stained with 2-(p-iodophenyl)-3-(p-nitrophenyl)-5-phenyl tetrazolium chloride $(0.5 \mathrm{mg} / \mathrm{ml})$ for enumeration of colonies containing $>20$ cells. Purified $\beta$-TGF was prepared by acid/ethanol extraction of normal human platelets and subsequent chromatography on Bio-Gel P-60 (Bio-Rad Laboratories, Richmond, CA) as previously described (28). This purified factor elicited a half-maximal increase in colony formation at a protein concentration of $25 \mathrm{ng} / \mathrm{ml}$.

\section{Column chromatography}

Concentrates $(5 \mathrm{ml})$ were applied to $2.5 \times 90$-cm columns of Ultrogel AcA 44 (LKB Co., Gaithersburg, MD) and eluted by ascending flow with $0.1 \mathrm{~N}$ acetic acid in $50 \mathrm{mM}$ ammonium acetate, $\mathrm{pH} 4.1$, at a flow rate of $22 \mathrm{ml} / \mathrm{h}$. Fractions $(4 \mathrm{ml})$ were collected, optical density at 280 $\mathrm{nm}$ was determined, and selected fractions were lyophilized and redissolved in medium for direct bioassay of bone-resorbing activity.

\section{Other procedures}

Immunoreactive PTH was measured in plasma, concentrated cell medium, or urine using chicken antiserum CK-67, which exhibits specificity for the amino-terminal region of the PTH sequence (29). The sensitivity of the PTH immunoassay for human PTH(1-34) was $\sim 1-2 \mathrm{pg} /$ tube. Serum $1,25(\mathrm{OH})_{2} \mathrm{D}$ was measured by specific radioimmunoassay in the laboratory of Dr. Thomas Clemens at the Regional Bone Center, Helen Hayes Hospital, West Haverstraw, NY, where normal levels were 20$65 \mathrm{pg} / \mathrm{ml}$. Cyclic AMP was measured in appropriately diluted (1:100 to 1:1000) urine by a commercial radioimmunoassay (New England Nuclear) that was highly specific for cyclic AMP. Serum and urinary creatinine were measured in the hospital's Clinical Chemistry Laboratory. Values for total urinary cyclic AMP ( $\mathrm{nmol} / 100 \mathrm{ml}$ of glomerular filtrate) measured by these techniques in normal subjects $(3.1 \pm 0.4, n=6)$ and in patients with primary hyperparathyroidism $(9.9 \pm 0.8, n=7)$, hypercalcemia owing to solid tumors not metastatic to bone $(7.0 \pm 1.2, n$ $=12$ ), and hypercalcemia owing to hematologic malignancy $(3.1 \pm 1.4$, $n=3$ ) were in agreement with data provided by the supplier of the cyclic AMP kits and with results previously published by others $(30,31)$.

For organic extraction, aliquots of medium and urine concentrates were diluted to $1 \mathrm{ml}$ with saline, acidified to $\mathrm{pH} 3.5$ with glacial acetic acid, and extracted three times with 3 vol of ethyl acetate. In control experiments, this procedure resulted in over $98 \%$ extraction of $\left[{ }^{3} \mathrm{H}\right] \mathrm{PGE}_{2}$ added as an indicator of the efficiency of the separation. The combined ethyl acetate extracts were evaporated to dryness under a stream of nitrogen and redissolved in medium for bioassay. The aqueous phases were dialyzed against $140 \mathrm{mM} \mathrm{NaCl}, 1 \mathrm{mM}$ sodium phosphate, $\mathrm{pH} 7.4$, and diluted with medium prior to bioassay.

\section{Results}

Cultured tumor cells from this patient ("TCC cells") were tumorigenic when administered subcutaneously to athymic nude mice. Moreover, the majority of tumor-bearing mice developed hypercalcemia (Fig. 1) by 8 wk in the absence of bony metastases either at autopsy or by radionuclide bone scanning (four mice). Renal function remained normal in the tumor-bearing animals.

Concentrates of both the patient's urine and of conditioned medium from her cultured tumor cells contained potent boneresorbing activity when tested in the mouse calvarial resorption assay (Fig. 2). Moreover, the biologic and chemical properties of the activity in conditioned medium and the patient's urine were similar by a variety of independent criteria. Thus, in both cases, the activity was nondialyzable and was not destroyed by exposure to denaturing (8 $\mathrm{M}$ urea) or reducing (65 mM dithiothreitol) agents (Table I). Activity was stable upon heating to $56^{\circ} \mathrm{C}$ for $45 \mathrm{~min}$ but was lost upon boiling for $10 \mathrm{~min}$. No PTH immunoreactivity was detectable in either urine or medium concentrates at dilutions active in the resorption bioassay, and levels of $\mathrm{PGE}_{2}$ were $<100 \mathrm{pM}$, which is 100 -fold lower than the detection limit of the resorption assay for $\mathrm{PGE}_{2}$ (Fig. 2). The possibility that other lipid-soluble substances (other prostaglandins, vitamin D metabolites, vitamin A) might be responsible for the bone-resorbing activity in TCC medium or urine concentrates was addressed by extracting these concentrates with ethyl acetate and then testing the organic extracts and residual aqueous phases for bone-resorbing activity. As shown in Table I, all of the bone-resorbing activity in both preparations remained

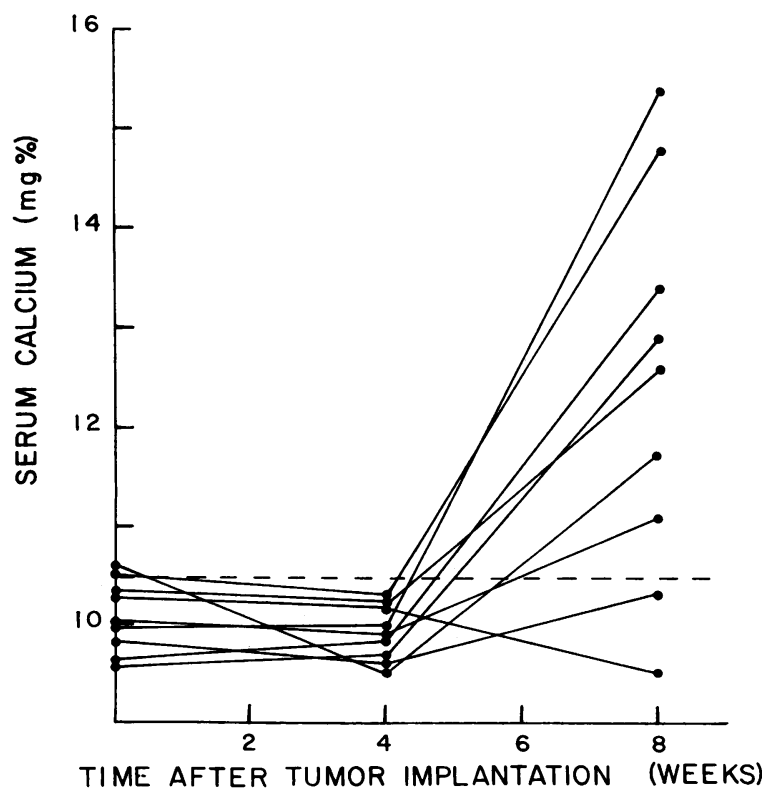

Figure 1. Hypercalcemia in athymic nude mice bearing TCC tumors. Tumor cells $\left(1-2 \times 10^{6}\right)$ were injected subcutaneously into the flanks of nude mice, and blood was obtained via tail vein at 4-wk intervals. The upper limit of normal (mean $+2 \mathrm{SD}$ ) is indicated by the dashed line. Serum creatinine (mean \pm SEM) was $0.61 \pm 0.04 \mathrm{mg} / \mathrm{dl}$ initially and $0.55 \pm 0.03 \mathrm{mg} / \mathrm{dl}$ at $8 \mathrm{wk}$. 


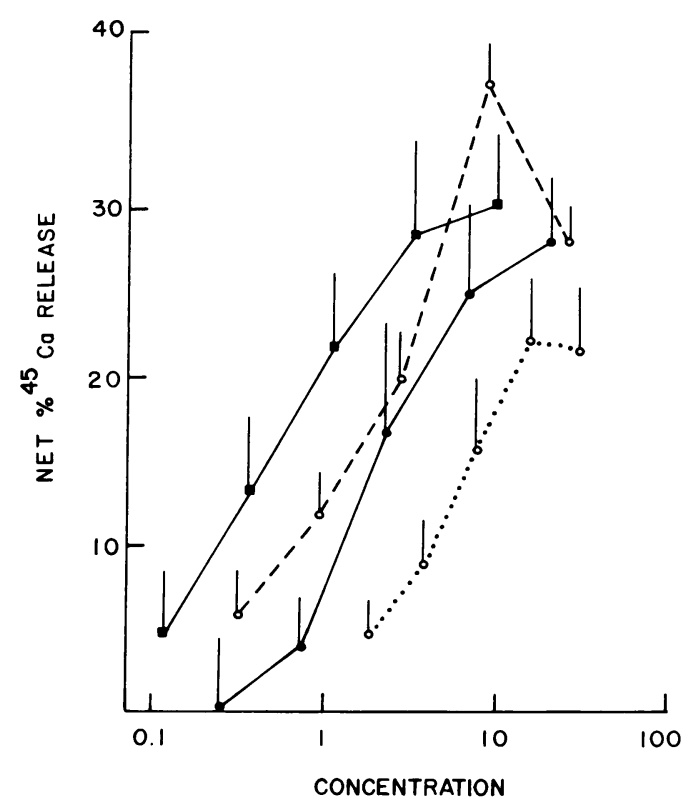

Figure 2. Bone resorption induced by concentrates of TCC medium and patient urine. Concentrates (100-fold) prepared by ultrafiltration of TCC cell medium ( $\bullet$ ) or the patient's urine ( $\bullet$ ) were assayed for bone-resorbing activity in 72-h cultures. Results are expressed as the increment in percent total bone radiocalcium released over that of untreated control bones for groups of five bones (mean \pm SEM) in each experiment. Doses of medium or urine concentrate are given as microliters/milliliter of concentrate in the final assay medium. The effects of bPTH(1-34) (nanomolar) (0-- - O) and PGE $_{2}$ (nanomolar $\left.\times 10^{-1}\right)(0 \cdots 0)$ in this assay are also shown. Control resorption in the experiments with TCC medium, patient urine, bPTH(1-34), and $\mathrm{PGE}_{2}$ was $23 \pm 3,18 \pm 2,17 \pm 1$ and $25 \pm 3 \%$, respectively.

in the aqueous phases, and none was found in the corresponding organic extracts.

In addition, resorption induced by both concentrates was almost completely blocked by calcitonin, and neither preparation caused increased release of radiocalcium from bones previously devitalized by repetitive freeze-thawing (Table I). Gel filtration chromatography of both patient urine and TCC medium concentrates demonstrated a single major peak of bone-resorbing activity that eluted with an apparent molecular weight of $\sim 15,000$ (Fig. 3).

Both urine- and cell-derived resorbing activities were associated with increased release of immunoreactive $\mathrm{PGE}_{2}$ by the calvarial bones, and, moreover, in both cases the bone-resorbing activity was inhibited by addition of indomethacin to the bone resorption bioassay (Table II). By contrast, PTH also increased $\mathrm{PGE}_{2}$ release from these bones (Table II), but the increased resorption induced by this hormone was unaffected by indomethacin, despite virtually complete blockade of $P G E_{2}$ release by the drug. The possibility that bone-resorbing and prostaglandinstimulating activities in the TCC medium were properties of the same molecule was further supported by the demonstration of coelution of these two activities during gel-filtration chromatography (Fig. $3 A$ and $B$ ).

Concentrated urine and cell medium were tested for evidence of PTH-like adenylate cyclase-stimulating activity using several in vitro bioassays. When cyclic AMP was measured in the medium of cultured calvarial bones undergoing resorption $3 \mathrm{~d}$ after addition of maximal doses of TCC medium, no evidence of delayed stimulation of cyclic AMP production was observed, whereas increases in medium cyclic AMP were seen when bones were treated with doses of $\mathrm{PGE}_{2}$ causing comparable bone resorption (see legend to Table III). At doses causing maximal activity in the bone resorption assay, neither TCC medium nor patient urine concentrate increased adenylate cyclase activity acutely in isolated canine renal membranes (Fig. 4) or in intact ROS $17 / 2.8$ cells $(22,25)$ (data not shown). Similarly, when PTH and TCC medium concentrates were tested at doses that caused maximal bone resorption, no acute increase in release of cyclic AMP by calvarial bones or rat osteosarcoma cells was observed in response to TCC medium concentrates, whereas

Table I. Chemical and Biologic Properties of TCC-derived Bone-resorbing Activity

\begin{tabular}{|c|c|c|c|}
\hline \multirow[b]{2}{*}{ Experiment } & \multicolumn{3}{|c|}{ Bone resorption* $^{*}$} \\
\hline & $\begin{array}{l}\text { Control } \\
\text { medium }\end{array}$ & TCC medium & $\begin{array}{l}\text { Patient } \\
\text { urine }\end{array}$ \\
\hline \multicolumn{4}{|l|}{ No. 1} \\
\hline Untreated & $17 \pm 1$ & $46 \pm 4$ & $30 \pm 4$ \\
\hline Dialyzed $(3,500 \mathrm{~mol} \mathrm{wt})$ & $18 \pm 1$ & $45 \pm 3$ & $39 \pm 1$ \\
\hline Urea $(8 \mathrm{M} \times 4 \mathrm{~h})$ & $18 \pm 2$ & $49 \pm 2$ & $44 \pm 4$ \\
\hline \multicolumn{4}{|l|}{ No. 2} \\
\hline Untreated & $18 \pm 3$ & $37 \pm 3$ & $50 \pm 5$ \\
\hline Heated $\left(56^{\circ} \mathrm{C} \times 45 \mathrm{~min}\right)$ & $13 \pm 3$ & $38 \pm 3$ & $43 \pm 4$ \\
\hline Boiled $\left(100^{\circ} \mathrm{C} \times 10 \mathrm{~min}\right)$ & $11 \pm 1$ & $13 \pm 1 \ddagger \pi$ & $13 \pm 1 \neq \cdot \pi$ \\
\hline \multicolumn{4}{|l|}{ No. 3} \\
\hline Untreated & $10 \pm 2$ & $23 \pm 3$ & $17 \pm 2$ \\
\hline \multicolumn{4}{|l|}{ Ethyl acetate extraction } \\
\hline Aqueous phase & $12 \pm 1$ & $29 \pm 4$ & $30 \pm 4$ \\
\hline Organic phase & $13 \pm 1$ & $14 \pm 1 \ddagger$ & $11 \pm 1 \neq \sqrt[\pi]{1}$ \\
\hline \multicolumn{4}{|l|}{ No. 4} \\
\hline Untreated & $25 \pm 3$ & $40 \pm 4$ & $41 \pm 2$ \\
\hline Dithiothreitol (65 mM) & $27 \pm 3$ & $36 \pm 2$ & $40 \pm 4$ \\
\hline \multicolumn{4}{|l|}{ No. 5} \\
\hline Untreated & $13 \pm 2$ & $37 \pm 3$ & $35 \pm 4$ \\
\hline Devitalized bones & $8 \pm 1$ & $8 \pm 1 \ddagger \cdot \pi$ & $8 \pm 1 \ddagger \pi$ \\
\hline Calcitonin $(2 \mathrm{U} / \mathrm{ml})$ & $8 \pm 1$ & $14 \pm 1 \pi$ & $12 \pm 1 \pi$ \\
\hline
\end{tabular}

Aliquots of concentrates were diluted to $1 \mathrm{ml}$ with $140 \mathrm{mM} \mathrm{NaCl} / \mathrm{l}$ mM sodium phosphate, $\mathrm{pH} 7.4$ ("saline phosphate") and treated as indicated prior to further dilution with assay medium and addition to bone cultures. Samples incubated in $8 \mathrm{M}$ urea or $65 \mathrm{mM}$ dithiothreitol $\left(37^{\circ} \mathrm{C} \times 2 \mathrm{~h}\right)$ were dialyzed against saline phosphate before dilution and bioassay. Bones were devitalized by three cycles of repetitive freeze-thawing. Final dilutions in the bioassay of control medium, TCC cell medium, and patient urine concentrates were 1:100, 1:100, and 1:500, respectively. In experiment 5 , resorption induced by $50 \mathrm{ng} /$ $\mathrm{ml}$ of bPTH(1-34) $(42 \pm 2 \%)$ was reduced to $12 \pm 1 \%$ in the presence of calcitonin $(P<0.05)$. Experiments shown were repeated at least three times each using different preparations of medium and urine concentrates, with similar results.

* Values shown are mean \pm standard error of the mean of the percent of total bone ${ }^{45} \mathrm{Ca}$ released in $72 \mathrm{~h}$ for groups of five bones. Unless indicated ( $\ddagger)$, all results with TCC medium or patient urine are significantly different from those for the corresponding control media $(P$ $<0.05$ ).

I Significantly different from untreated controls $(P<0.05)$. 


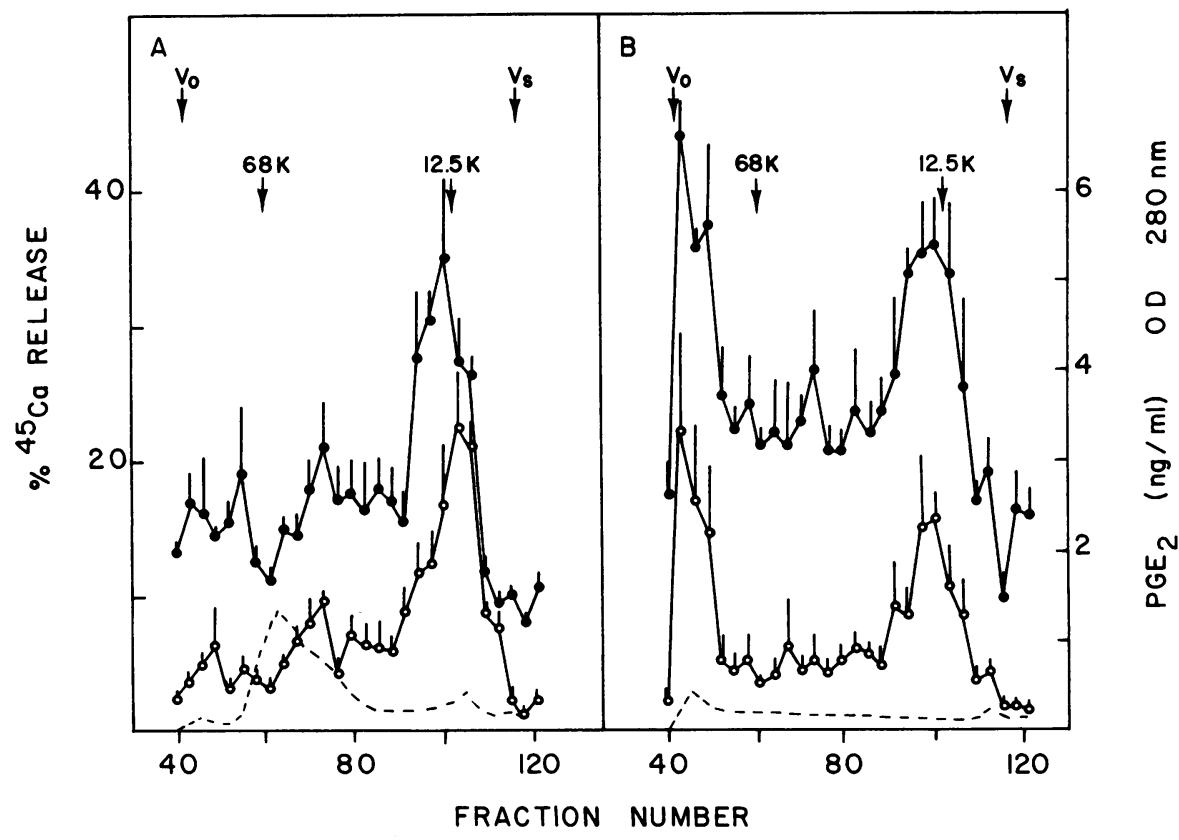

Figure 3. Ultrogel AcA 44 chromatography of concentrated TCC medium and patient urine. $(A)$ Concentrated TCC me$\operatorname{dium}(5 \mathrm{ml})$ was applied to a $2.4 \times 90-\mathrm{cm}$ column and eluted with $0.1 \mathrm{M}$ acetic acid in $50 \mathrm{mM}$ ammonium acetate, $\mathrm{pH} 4.1$. Selected fractions $(4 \mathrm{ml})$ were lyophilized, redissolved in $0.2 \mathrm{ml}$ of $10 \mathrm{mM}$ acetic acid, diluted to $16 \mathrm{ml}$ with medium, and added to the calvarial bioassay for measurement of bone resorption (๑), expressed as of percent ${ }^{45} \mathrm{Ca}$ (mean $\pm \mathrm{SEM}$ ) released in $72 \mathrm{~h}$ for groups of five bones. Absorbance at $280 \mathrm{~nm}$ is shown (-- ), as is medium $\mathrm{PGE}_{2}$ at $72 \mathrm{~h}$ (mean $\pm \mathrm{SEM}$ for groups of five bones) (O). Elution positions ( $\mathrm{K}$, thousands in mol wt) of blue dextran $\left(\mathrm{V}_{0}\right)$, bovine albumin, cytochrome $c$, and ${ }^{45} \mathrm{CaCl}_{2}\left(\mathrm{~V}_{\mathrm{g}}\right)$ are indicated. (B) As in $A$, except that the sample was 5 $\mathrm{ml}$ of concentrated patient urine and only $1 \mathrm{ml}$ of selected fractions was lyophilized for bioassay. When the remaining eluate in fractions 40-55 was pooled, lyophilized, and incubated in $8 \mathrm{M}$ urea for $2 \mathrm{~h}$ before reapplication to the column, $\sim 60 \%$ of the resorbing activity eluted in a peak at fraction 100 and the remainder again eluted near the void volume of the column.

PTH elicited the expected large increments in cyclic AMP (Table III). Because slight inhibition of basal renal membrane adenylate cyclase occurred at higher doses of TCC medium (Fig. 4), we studied the response of these membranes to $\mathrm{bPTH}(1-34)$ in the presence and absence of maximal levels of TCC medium concentrate $(10 \mu \mathrm{l} / \mathrm{ml})$. As shown in Fig. 4 , the adenylate cyclase response to bPTH(1-34) was inhibited slightly by added crude TCC medium concentrate. Comparable results were observed with the osteosarcoma cells (Table III). This apparently nonspecific inhibition seems inadequate to account for the complete absence of adenylate cyclase responsiveness to TCC medium alone, however.

Active TCC medium concentrates were also tested for the presence of constituents that might bind to receptors for EGF (Fig. 5). Although binding was reduced slightly below that of control wells in the presence of TCC concentrate, this was also true of control medium concentrate, and no dose-response relation was evident in either case. These data indicate that TCC medium concentrates, at dilutions (1:50 or more) maximally active in the bone resorption assay, must contain $<0.1 \mathrm{ng} / \mathrm{ml}$ of EGF-equivalent receptor binding activity. By contrast, EGF elicits maximal resorption of mouse calvaria in vitro only at doses higher than $1 \mathrm{ng} / \mathrm{ml}$ (32), and then only in the presence of fetal bovine or calf serum (not used in our studies). The presence of TGF activity in medium concentrates was also sought by testing for induction of anchorage-independent growth of normal rat kidney fibroblasts in soft agar in the presence and absence of EGF. At doses as high as $100 \mu \mathrm{l} / \mathrm{ml}$, however, TCCcell medium concentrates failed to stimulate significantly any growth of fibroblast colonies after $7 \mathrm{~d}$, whereas purified plateletderived $\beta$-TGF elicited up to 200 colonies per well (Table IV). The response to platelet $\beta$-TGF was not inhibited in the presence of $20 \mu \mathrm{l} / \mathrm{ml}$ of TCC medium (not shown).

\section{Discussion}

Urothelial cancers are frequently associated with humoral hypercalcemia (3), and the patient reported here exhibited the

Table II. Prostaglandin Dependence of TCC-derived Bone-resorbing Activity

\begin{tabular}{|c|c|c|c|c|}
\hline \multirow[b]{2}{*}{ Preparation } & \multicolumn{2}{|l|}{ Untreated } & \multicolumn{2}{|c|}{ Indomethacin } \\
\hline & Resorption & Medium PGE 2 & Resorption & Medium PGE 2 \\
\hline & \% & $p g / m l$ & \% & $p g / m l$ \\
\hline Control medium & $17 \pm 1$ & $130 \pm 30$ & $11 \pm 1^{*}$ & $18 \pm 2^{*}$ \\
\hline bPTH(1-34) $(50 \mathrm{ng} / \mathrm{ml})$ & $45 \pm 2$ & $690 \pm 180$ & $39 \pm 2$ & $8 \pm 8^{*}$ \\
\hline Patient urine (1:500) & $42 \pm 1$ & $1800 \pm 100$ & $12 \pm 1^{*}$ & $1 \pm 1^{*}$ \\
\hline TCC medium $(1: 100)$ & $38 \pm 3$ & $1100 \pm 130$ & $14 \pm 2 *$ & (Undetect.)* \\
\hline
\end{tabular}

Bones were cultured as indicated in the presence or absence of indomethacin $(10 \mu \mathrm{M})$. Values for bone resorption are percent ${ }^{45} \mathrm{Ca}$ release (mean \pm SEM), as in legend to Table I. Concentrations of $\mathrm{PGE}_{2}(\mathrm{pg} / \mathrm{ml})$ in the medium of the bone cultures after $72 \mathrm{~h}$ are expressed as mean \pm SEM for the groups of five bones. * Significantly different from untreated controls $(P<0.05)$. 


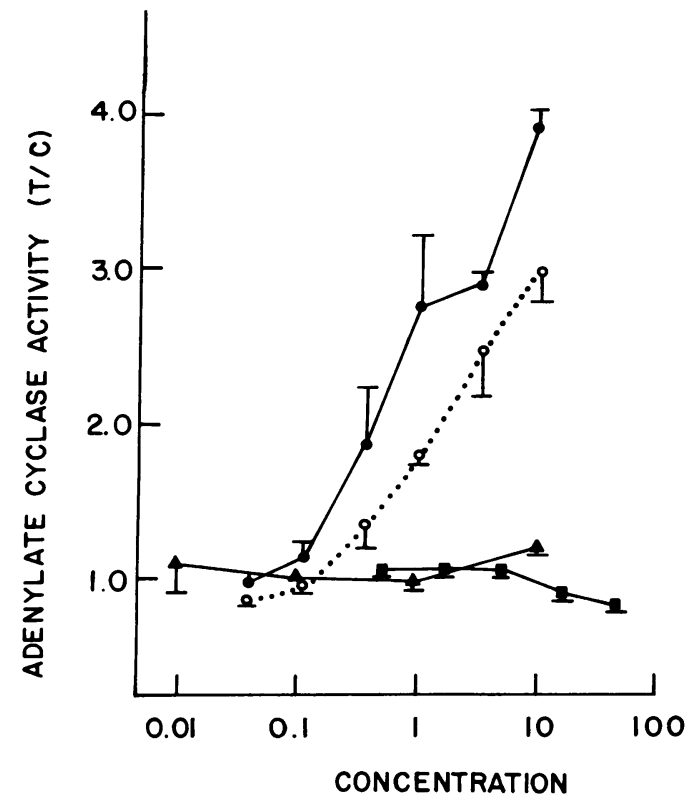

Figure 4. Lack of stimulation of canine renal membrane adenylate cyclase by TCC factor. Adenylate cyclase activity, expressed as treatedto-control ratios $(T / C)$, is shown in response to graded doses of concentrated TCC medium alone $(\square)$, concentrated patient urine $(\Delta)$, standard bPTH(1-34) (๑), and bPTH(1-34) in the presence of $10 \mu \mathrm{l} / \mathrm{ml}$ of TCC medium concentrate (o). Concentrations of TCC medium or urine are given as microliters per milliliter and of PTH as nanomolar. Results shown are mean \pm standard error of the mean for triplicate determinations and are representative of five separate experiments.

characteristic clinical features of the humoral hypercalcemia syndrome $(1,7)$. Thus, hypercalcemia occurred in the absence of radiographically demonstrable bone metastases, serum phosphorus and $1,25(\mathrm{OH})_{2} \mathrm{D}$ were low, and plasma $\mathrm{iPTH}$ was undetectable, in spite of which urinary cyclic AMP excretion was not suppressed. The severity of the hypercalcemia fluctuated with treatment of the patient's underlying malignancy, and therapy with glucocorticoids and orthophosphate were not clearly successful in relieving the hypercalcemia. The virtual replacement of the patient's bladder by invasive tumor provided a unique opportunity to collect directly the products of tumorcell secretion in vivo. Moreover, the establishment of the patient's tumor cells as a continuous cell line in vitro permitted direct study of the nature of the cellular product(s) potentially responsible for the humoral hypercalcemia.

The similarity, both physicochemical and biologic, of the bone-resorbing factors identified in concentrates of this patient's urine and of culture medium conditioned by exposure to her tumor cells in vitro suggests that these TCC cells have continued to release the same active factor in vitro as had been produced previously in vivo. Moreover, the occurrence of humoral hypercalcemia in athymic nude mice bearing TCC tumors strongly supports the hypothesis that the bone-resorbing factor released by these cells in vitro causes hypercalcemia in vivo and was likely responsible for the patient's hypercalcemia. Nevertheless, direct proof of this hypothesis awaits the availability of highly purified bone-resorbing factor.

The bone-resorbing factor released by TCC cells exhibits properties that distinguish it from several other factors previously
Table III. Effect of TCC Medium on Bone Cell Cyclic AMP Production

\begin{tabular}{lcc}
\hline Preparation & Mouse calvarial bones & Rat osteosarcoma cells \\
\hline & pmol/bone per 10 min & pmol/well per 10 min \\
$\begin{array}{l}\text { Control } \\
\text { bPTH(1-34) }\end{array}$ & $15 \pm 5$ & $21 \pm 10$ \\
$\quad 1 \times 10^{-8} \mathrm{M}$ & $93 \pm 15$ & \\
$\quad 1 \times 10^{-7} \mathrm{M}$ & $346 \pm 48$ & $442 \pm 86$ \\
$\begin{array}{l}\text { TCC medium I } \\
\text { No additions } \\
+ \text { bTPH( }(1-34)\end{array}$ & $10 \pm 32$ & $741 \pm 163$ \\
$\quad\left(1 \times 10^{-8} \mathrm{M}\right)$ & $79 \pm 14$ & $5 \pm 3$ \\
$\begin{array}{c}\text { TCC medium II } \\
\text { No additions } \\
+ \text { bPTH( }(1-34) \\
\quad\left(1 \times 10^{-8} \mathrm{M}\right)\end{array}$ & $91 \pm 17$ & $253 \pm 74$ \\
\hline
\end{tabular}

Incubations were conducted at $37^{\circ} \mathrm{C}$ as described in Methods. Two different preparations of TCC medium concentrate were tested (I and II), both with and without added bPTH(1-34). Results are expressed as the mean \pm standard error of the mean for groups of four bones or six wells of ROS 17/2.8 cells. When calvaria were incubated for $72 \mathrm{~h}$ with TCC medium $(10 \mu \mathrm{l} / \mathrm{ml}), \mathrm{PGE}_{2}(100 \mathrm{ng} / \mathrm{ml})$, or control medium alone, percent ${ }^{45} \mathrm{Ca}$ release was $33 \pm 4,40 \pm 4$, and $14 \pm 2$, respectively, whereas medium cyclic AMP (pmol/ml) was $10 \pm 1,21 \pm 2$ and $10 \pm 1$.

* Significantly different from bPTH(1-34) $\left(10^{-8} \mathrm{M}\right)$ alone $(P<0.05)$.

implicated in the pathogenesis of humoral hypercalcemia of malignancy. Direct measurements of PTH and $\mathrm{PGE}_{2}$ in active medium concentrates indicate that these agents could not be responsible for the resorbing activity observed in such preparations. That the resorbing activity is retained by $3,500-\mathrm{mol} w t$ dialysis membranes and partitions into the aqueous phase during organic extractions also provides evidence against a role for other prostaglandins, retinoids, or vitamin D metabolites. The TCC factor is distinguished from osteoclast-activating factor (OAF) purified from tonsillar tissue by its larger apparent molecular weight $(15,000$ vs. 9,000$)$ and the lack of stimulation of bonecell cyclic AMP production (16). OAF derived from leukocytes is similar in size to the TCC factor but, unlike the TCC factor, leukocyte OAF does not cause bone resorption via a prostaglandin-dependent mechanism (33). Resistance to denaturing concentrations of urea also indicates that a noncovalent subunit structure is probably not required for biologic activity of the TCC factor.

Bone resorption induced by the TCC factor in vitro appears to be dependent upon stimulation of prostaglandin synthesis in the bone tissue, in that large increments in medium $\mathrm{PGE}_{2}$ occur in these cultures and pretreatment of the bones with indomethacin effectively blocks resorption induced by this material. We have previously reported similar observations in the case of another human tumor-cell line (melanoma) (34), and others have reported prostaglandin-dependent bone-resorbing activity in extracts of a number of tumors associated with hypercalcemia (35). Although only measurements of $\mathrm{PGE}_{2}$ are reported here, preliminary experiments in our laboratory with radiolabeled arachidonic acid show that $\mathrm{PGE}_{2}$ and 6-keto-PGF $1 \alpha$, the major metabolite of prostacyclin, are the principal prostaglandins syn- 


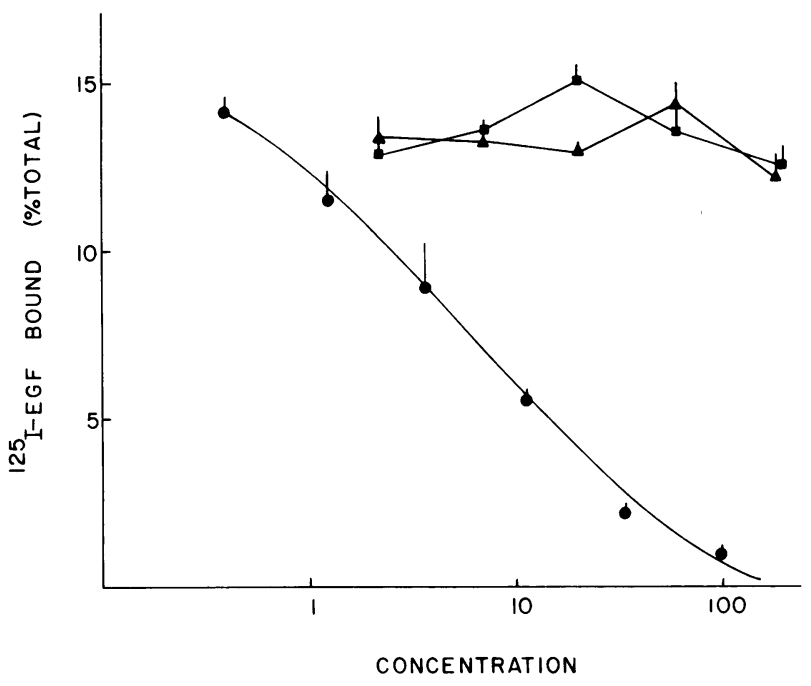

Figure 5. Absence of EGF receptor-binding activity in TCC medium concentrate. Incubations of TCC medium concentrate ( $\bullet$ ), control medium concentrate $(\Delta)$, and purified murine EGF $(\bullet)$ with ${ }^{125}$ I-EGF and A431 cells were conducted as described in Methods. Each point represents the percent total ${ }^{125} \mathrm{I}$-EGF bound (mean \pm SEM) for groups of four wells each. Control binding in the absence of added EGF was $15.2 \pm 0.7 \%$. The concentrations of test agents are given as nanograms per milliliter for EGF and as microliters per milliliter for the medium concentrates (100-fold). When tested for bone resorbing activity (at 20 $\mu \mathrm{l} / \mathrm{ml}$ ), these preparations of control and TCC medium concentrates elicited $25 \pm 3$ and $51 \pm 3 \%{ }^{45} \mathrm{Ca}$ release, respectively (assay control, $25 \pm 2 \%$ ).

thesized by calvarial bones in response to the TCC factor. These are the same prostaglandins observed by others in cultures of mouse bones resorbing in response to phorbol esters or EGF $(32,36)$. Because of the heterogeneity of cell populations within the calvarial tissue, the precise cellular origin of the prostaglandins measured in the medium of bones treated with TCC factor remains unknown. Moreover, the mechanism(s) whereby increased prostaglandin release initiates accelerated bone resorption induced by this material is also unclear. It is of interest that PTH also causes increased medium $\mathrm{PGE}_{2}$ in these bone cultures (Table II) but that indomethacin, although it blocks the increment in $\mathrm{PGE}_{2}$, fails to inhibit the resorption induced by this hormone.

Table IV. Absence of TGF Activity in TCC Medium Concentrate

\begin{tabular}{llc}
\hline & \multicolumn{2}{l}{ Colony-stimulating activity* } \\
\cline { 2 - 3 } Preparation & -EGF & +EGF \\
\hline Control & 0 & 12 \\
$\beta$-TGF & & 110 \\
$25 \mathrm{ng} / \mathrm{ml}$ & 0 & 200 \\
$2,500 \mathrm{ng} / \mathrm{ml}$ & 0 & 11 \\
TCC medium & & 8 \\
$10 \mu \mathrm{l} / \mathrm{ml}$ & 0 &
\end{tabular}

This preparation of TCC medium concentrate elicits maximal bone resorption in vitro at $30 \mu \mathrm{l} / \mathrm{ml}$.

* Colonies ( $>20$ cells) per microtiter well after $7 \mathrm{~d}$ (mean of duplicates). Concentration of EGF is $5 \mathrm{ng} / \mathrm{ml}$.
These observations indicate that the nature of the biologic consequences of increased prostaglandin production in bone may depend upon the particular agent stimulating this production, the identity of the cells responsible for the augmented prostaglandin synthesis, or, possibly, the pattern of arachidonate metabolites produced. The potent inhibitory effect of calcitonin seen in our studies suggests that increased osteoclastic activity underlies the resorptive effects of the factor, although the synthesis of prostaglandins and, possibly, of a prostaglandin-dependent regulator of osteoclast activity might occur in adjacent osteoblasts in the calvarial tissue (37). The increased release of prostaglandins by bone in response to this or similar factors secreted by tumors in patients with humoral hypercalcemia could account for the elevated levels of plasma prostaglandins often seen in such patients (13), the occasional response of humoral hypercalcemia to indomethacin or aspirin $(1,11,13)$, and the observation that tumor prostaglandin content often correlates poorly with hypercalcemia (38).

The involvement of prostaglandins in the resorptive response of mouse calvaria to TCC factor is analogous to the effects of some bone-resorbing growth factors, including EGF and plateletderived growth factor, in this tissue $(32,39)$. This is of particular interest in light of the hypothesis of Mundy et al. $(1,18,19)$ that tumor-derived growth factors may mediate the humoral hypercalcemia syndrome. We were unable to detect either EGF receptor-binding activity or $\beta$-TGF activity in concentrated cell medium, however, even at doses much higher than those required to elicit maximal bone resorption in vitro. Moreover, calvarial bone resorption induced by TCC medium occurs in the absence of added calf serum, whereas EGF stimulates resorption in this system only in the presence of calf serum (unpublished observations). Finally, other common features of tumor-derived growth factors, including inactivation by reducing agents and stability to boiling (40), are not shared by the TCC factor. It therefore seems unlikely that the TCC-derived resorbing factor is also a transforming growth factor, although further studies with more purified factor will be necessary to exclude this possibility definitively.

Recently, PTH-like macromolecular factors have been described in extracts of tumors and in culture medium from tumor cell lines obtained from hosts with humoral hypercalcemia (2022). These factors, like PTH, stimulate adenylate cyclase activity in renal membranes or osteoblast-like bone cells, an effect that can be blocked by synthetic inhibitory analogs of PTH (20-22). Analogous observations have been made using a highly sensitive renal cytochemical bioassay (20). It has thus been proposed that such factors, although immunochemically and chromatographically distinct from PTH, might nevertheless interact with PTH receptors in bone and kidney to initiate increased bone resorption and decreased renal tubular phosphate reabsorption by cyclic AMP-mediated mechanisms (20). Such effects might account for hypercalcemia, hypophosphatemia, and high nephrogenous cyclic AMP excretion seen in humoral hypercalcemia, even though other common features of the syndrome, including low levels of serum $1,25(\mathrm{OH})_{2} \mathrm{D}$, elevated fractional excretion of calcium, and histologically apparent uncoupling of bone resorption and formation rates (5), would still not be readily explained. In light of these reports, we carefully examined the possibility that such a PTH-like factor might be present in our TCC medium or urine concentrates. Extensive studies of the possible effects of these concentrates on cyclic AMP production in a variety of 
PTH-responsive bioassays, including the calvarial bone cultures used for the resorption measurements, failed to reveal any evidence of such a factor, however. This was true even at doses well above those that elicit maximal activity in the bone resorption bioassay. The absence of adenylate cyclase-stimulating activity appears not to be due to the presence in these concentrates of nonspecific inhibitors of the bioassay. These observations clearly indicate that the TCC factor induces bone resorption in vitro by a mechanism not involving activation of PTH-receptorlinked adenylate cyclase. The source of the abundant cyclic AMP present in our patient's urine is not known with certainty. Although her total urinary cyclic AMP excretion (4.8 nmol/100 $\mathrm{ml}$ glomerular filtrate) is such that we cannot unambiguously classify this patient into either the high- or low-cyclic AMP groups proposed by Stewart et al. (7), this amount of urinary cyclic AMP seems inappropriate in the setting of persistently undetectable serum iPTH. It is possible that the tumor cells in her urinary tract may have released large amounts of cyclic AMP directly into the urine, although we have not observed high concentrations of cyclic AMP in fresh medium from the TCC cell cultures. Because plasma cyclic AMP was not measured, it is possible that much of the cyclic AMP present in the patient's urine derived from glomerular filtration. Finally, others have reported elevations of nephrogenous cyclic AMP in normocalcemic cancer patients $(31,41)$, which suggests that this abnormality may be a general feature of some malignancies that is unrelated to coexisting abnormalities in calcium metabolism.

In summary, we have identified a potent macromolecular bone-resorbing factor released in vitro by a tumor cell line established from a patient with humoral hypercalcemia of malignancy. This cell line, which is tumorigenic and causes humoral hypercalcemia in athymic nude mice, provides a new experimental model for study of the human humoral hypercalcemia syndrome. The factor released by these cells in vitro is physically and biologically similar to activity recovered from the patient's urine, which had been in direct contact with a large mass of tumor tissue. Our studies suggest that this factor is different from others previously implicated as causes of the humoral hypercalcemia syndrome and that its effects on bone resorption are mediated by an increase in prostaglandin synthesis in bone cells. Purification and further study of the mechanism of action of this factor, both in vivo and in vitro, should lead to better understanding of the pathogenesis of humoral hypercalcemia of malignancy.

\section{Acknowledgments}

We are grateful to Dr. Barbara Bassil for providing tumor tissue from this patient; Dr. Gideon Rodan of the Department of Oral Biology, University of Connecticut, Farmington, for testing of adenylate cyclase activation in intact ROS cells; Dr. Thomas Clemens for measurement of $1,25(\mathrm{OH})_{2}$; Dr. Frank Castronova of the Radiation Safety Unit, Massachusetts General Hospital, for performance of radionuclide bone scans; Panfilo Federico for measurement of serum calcium and creatinine in nude mice; and Maureen Yotts and Karen Liaknickas for help in preparation of the manuscript. We also thank Dr. John Potts for helpful discussions and review of the manuscript.

This work was supported by grant CA-33320 from the National Cancer Institute. Dr. Bringhurst was recipient of a Medical Foundation Fellowship and a Research Fellowship of the American Cancer Society of Massachusetts, Inc.

\section{References}

1. Mundy, G. R., and T. J. Martin. 1982. The hypercalcemia of malignancy: pathogenesis and management. Metab. Clin. Exp. 31:12471277.

2. Myers, W. P. L. 1960. Hypercalcemia in neoplastic disease. Arch Surgery. 80:308-318.

3. Fisken, R. A., D. A. Heath, and A. M. Bold. 1980. Hypercalcaemia-a hospital survey. Q. J. Med. 196:405-418.

4. Coombes, R. C., M. K. Ward, P. B. Greenberg, C. J. Hillyard, B. R. Tulloch, R. Morrison, and G. F. Joplin. 1976. Calcium metabolism in cancer: studies using calcium isotopes and immunoassays for parathyroid hormone and calcitonin. Cancer. 38:2111-2120.

5. Stewart, A. F., A. Vignery, A. Silvergate, N. D. Ravin, V. Livolsi, A. E. Broadus, and R. Baron. 1982. Quantitative bone histomorphometry in humoral hypercalcemia of malignancy: uncoupling of bone cell activity. J. Clin. Endocrinol. Metab. 55:219-227.

6. Eilon, G., and G. R. Mundy. 1978. Direct resorption of bone by human cancer cells in vitro. Nature (Lond.). 276:726-728.

7. Stewart, A. F., R. Horst, L. J. Deftos, E. Cadman, R. Lane, and A. E. Broadus. 1980. Biochemical evaluation of patients with cancer associated hypercalcemia. N. Engl. J. Med. 303:1377-1383.

8. Benson, R. C., B. L. Biggs, B. M. Pickard, and C. D. Arnaud. 1974. Immunoreactive forms of circulating parathyroid hormone in primary and ectopic hyperparathyroidism. J. Clin. Invest. 54:175-181.

9. Greenberg, P. B., T. J. Martin, and H. S. Sutcliffe. 1983. Synthesis and release of parathyroid hormone by a renal carcinoma in cell culture. Clin. Sci. Mol. Med. 45:183-191.

10. Knill-Jones, R. P., R. M. Buckle, V. Parsons, M. S. Caene, and R. Williams. 1970. Hypercalcemia and increased parathyroid-hormone activity in a primary hepatoma. $N$. Engl. J. Med. 282:704-708.

11. Seyberth, H. W., G. V. Segre, J. T. Morgan, B. J. Sweetman, J. T. Potts, Jr., and J. A. Oates. 1975. Prostaglandins as mediators of hypercalcemia associated with certain types of cancer. N. Engl. J. Med. 293:1278-1283.

12. Greaves, M., K. J. Ibbotson, D. Atkins, and T. J. Martin. 1980. Prostaglandins as mediators of bone resorption in renal and breast tumors. Clin. Sci. (Oxf.). 58:201-210.

13. Brenner, D. E., H. A. Harvey, A. Lipton, and L. Demers. 1982. A study of prostaglandin $E_{2}$, parathormone, and response to indomethacin in patients with hypercalcemia of malignancy. Cancer. 49:556-561.

14. Mundy, G. R., R. A. Luben, L. G. Raisz, J. J. Oppenheim, and D. N. Buell. 1974. Bone-resorbing activity in supernatants from lymphoid cell lines. N. Engl. J. Med. 290:867-871.

15. Mundy, G. R., M. E. Rick, R. Turcotte, and M. A. Kowalski. 1978. Pathogenesis of hypercalcemia in lymphosarcoma cell leukemia. Am. J. Med. 65:600-606.

16. Luben, R. A. 1980. An assay for osteoclast-activating factor (OAF) in biological fluids: detection of OAF in the serum of myeloma patients. Cell. Immunol. 49:74-80.

17. Durie, B. G. M., S. E. Salmon, and G. R. Mundy. 1981. Relation of osteoclast activating factor production to extent of bone disease in multiple myeloma. Br. J. Haematol. 47:21-30.

18. Ibbotson, K. J., S. M. D’Souza, K. W. Ng, C. K. Osborne, M. Niall, T. J. Martin, and G. R. Mundy. 1983. Tumor-derived growth factor increases bone resorption in a tumor associated with humoral hypercalcemia of malignancy. Science (Wash. DC). 221:1292-1294.

19. Ibbotson, K. J., S. M. D'Souza, D. D. Smith, and G. R. Mundy. 1985. EGF receptor antiserum inhibits bone resorbing activity produced by a rat Leydig cell tumor associated with the humoral hypercalcemia of malignancy. Endocrinology. 116:469-471.

20. Stewart, A. F., K. L. Insogna, D. Goltzman, and A. E. Broadus. 1983. Identification of adenylate cyclase stimulating activity and cytochemical glucose-6-phosphate dehydrogenase stimulating activity in extracts of tumors from patients with humoral hypercalcemia of malignancy. Proc. Natl. Acad. Sci. USA. 80:1454-1458. 
21. Strewler, G. J., R. J. Williams, and R. A. Nissenson. 1983. Human renal carcinoma cells produce hypercalcemia in the nude mouse and a novel protein recognized by parathyroid hormone receptors. J. Clin. Invest. 71:769-774.

22. Rodan, S. B., K. L. Insogna, A. M. C. Vignery, A. F. Stewart, A. E. Broadus, S. M. D'Souza, D. R. Bertolini, G. R. Mundy, and G. A. Rodan. 1983. Factors associated with human hypercalcemia of malignancy stimulate adenylate cyclase in osteoblastic cells. J. Clin. Invest. 72:1511-1515.

23. Bringhurst, F. R., G. V. Segre, G. W. Lampman, and J. T. Potts, Jr. 1982. Metabolism of parathyroid hormone by Kupffer cells: analysis by reverse-phase high performance liquid chromatography. Biochemistry. 21:4252-4258.

24. Nissenson, R. A., S. R. Abbott, A. P. Teitelbaum, O. H. Clark, and C. D. Arnaud. 1981. Endogenous biologically active human parathyroid hormone: measurement by a guanyl nucleotide-amplified renal adenylate cyclase assay. J. Clin. Endocrinol. Metab. 52:840-846.

25. Rodan, S. B., M. K. Fischer, J. J. Egan, P. M. Epstein, and G. A. Rodan. 1984. The effect of dexamethasone on parathyroid hormone stimulation of adenylate cyclase in ROS 17/2.8 cells. Endocrinology. 115:951-958.

26. DeLarco, J. E., and G. J. Todaro. 1978. Growth factors from murine sarcoma virus-transformed cells. Proc. Natl. Acad. Sci. USA. 75: 4001-4005.

27. Roberts, A. B., L. C. Lamb, D. L. Newton, M. B. Sporn, J. E. DeLarco, and G. J. Todaro. 1980. Transforming growth factors: isolation of polypeptides from virally chemically transformed cells by acid/ethanol extraction. Proc. Natl. Acad. Sci. USA. 77:3494-3498.

28. Assoian, R. K., A. Komoriya, C. A. Myers, D. M. Miller, and M. B. Sporn. 1983. Transforming growth factor beta in human platelets. Identification of a major storage site, purification and characterization. J. Biol. Chem. 258:7155-7160.

29. Segre, G. V. 1983. Amino-terminal radioimmunoassays for human parathyroid hormone. Clinical disorders of Bone and Mineral Metabolism (Proceedings of the Frances and Anthony D'Anna Memorial Symposium, Detroit, MI, May 1983). In B. Frame, and J. T. Potts, Jr. editors. Excerpta Medica, Amsterdam. 14-17.

30. Broadus, A. E. 1981. Nephrogenous cyclic AMP. Rec. Prog. Horm. Res. 37:667-701.
31. Rude, R. K., C. F. Sharp, Jr., R. S. Fredericks, S. B. Oldham, N. Elbaum, J. Link, L. Irwin, and F. R. Singer. 1981. Urinary and nephrogenous adenosine 3'-5'-monophosphate in the hypercalcemia of malignancy. J. Clin. Endocrinol. 52:765-771.

32. Tashjian, A. H., Jr., and L. Levine. 1978. Epidermal growth factor stimulates prostaglandin production and bone resorption in cultured mouse calvaria. Biochem. Biophys. Res. Commun. 85:966-975.

33. Yoneda, T., and G. R. Mundy. 1979. Monocytes regulate osteoclast-activity factor production by releasing prostaglandins. J. Exp. Med. 150:338-350.

34. Bringhurst, F. R., B. E. Bierer, and G. V. Segre. 1984. Hypercalcemia of malignancy: soluble bone resorbing factors in established cultures of human tumor cells. Calcif. Tissue Int. 36:480. (Abstr.)

35. Minkin, C., R. S. Fredricks, S. Pokress, R. K. Rude, C. F. Sharp, Jr., M. Tong, and F. R. Singer. 1981. Bone resorption and humoral hypercalcemia of malignancy: stimulation of bone resorption in vitro by tumor extracts is inhibited by prostaglandin synthesis inhibitors. $J$. Clin. Endocrinol. Metab. 53:941-947.

36. Tashjian, A. H., Jr., J. L. Ivey, B. Delclos, and L. Levine. 1978. Stimulation of prostaglandin production in bone by phorbol diesters and melittin. Prostaglandins. 16:221-232.

37. Nolan, R. D., N. C. Partridge, H. M. Godfrey, and T. J. Martin. 1983. Cyclo-oxygenase products of arachidonic acid metabolism in rat osteoblast in culture. Calcif. Tissue Res. 35:294-297.

38. Kukreja, S. C., W. P. Shemerdiak, P. A. J. York, T. E. Lad, E. C. Abramson, P. A. Thomas, and J. Mir. 1982. Presence of prostaglandin $\mathrm{E}$ in lung tumors from normocalcemic patients. Am. J. Med. 72:737-742.

39. Tashjian, A. H., Jr., E. L. Hohmann, H. N. Antoniades, and L. Levine. 1982. Platelet-derived growth factor stimulates bone resorption via a prostaglandin-mediated mechanism. Endocrinology. 111:118-123.

40. Todaro, G. J., C. Fryling, and J. E. DeLarco. 1980. Transforming growth factors produced by certain human tumor cells: polypeptides that interact with epidermal growth factors. Proc. Natl. Acad. Sci. USA. 77:5258-5262.

41. Kukreja, S. C., W. P. Shemerdiak, T. E. Lad, and P. A. Johnson. 1980. Elevated nephrogenous cyclic AMP with normal serum parathyroid hormone levels in patients with lung cancer. J. Clin. Endocrinol. Metab. 51:167-169. 